\title{
PESQUISA DE MICRORGANISMO EM FORMIGAS NO ENTORNO DE UM HOSPITAL EM PRESIDENTE PRUDENTE - SP
}

Rafaella Garcia Pelegrini, Cintia Helena Santos Venturim Silva, Andre Carrion De Fares Pinto, Belquis Alves Dos Santos, Maria Do Socorro Alves, Sueli Cristina Schadeck Zago.

Universidade do Oeste Paulista - UNOESTE. Presidente Prudente, SP. E-mail: andrecf192734@gmail.com.

\begin{abstract}
RESUMO
Com o crescimento de áreas urbanas, tem-se notado deficiência da qualidade do saneamento básico, ocorrendo proliferação principalmente de formigas que para o âmbito hospitalar são consideradas preocupantes, pois podem transportar bactérias potencialmente patogênicas, gerando um grave problema de saúde publica, as infecções hospitalares. Este estudo avaliou se formigas capturadas no entorno de um hospital de Presidente Prudente - SP são transportadoras de bactérias potencialmente patogênicas. As formigas foram retiradas do local com um swab estéril e transferidas para tubos de ensaio contendo TSB (caldo de triptona de soja) e incubados à $37^{\circ} \mathrm{C}$ por 24 horas. Posteriormente semeadas em meios de culturas apropriados e realizadas todas as provas para identificação das bactérias. Foram encontrados $26 \%$ de bactérias potencialmente patogênicas das espécies Staphylococcus saprophyticus (11\%), Staphylococcus epidermidis (1\%), Enterobacter spp (3\%) e Klebsiella spp (11\%). Concluiu-se que as formigas capturadas no entorno de um hospital de Presidente Prudente transportam bactérias potencialmente patogênicas.
\end{abstract}

Palavras-Chave: Formigas, Infecção hospitalar, Bactérias.

\section{RESEARCH ON MICROORGANISMS IN ANTS NEAR A HOSPITAL IN PRESIDENTE PRUDENTE - SP}

\begin{abstract}
With the growth of urban areas, it has been noticed impairment of the quality of sanitation, especially occurring proliferation of ants to the hospital environment are considered worrisome since they can be carriers of potentially pathogenic bacteria, creating a serious public health problem which is hospital infections. This study evaluated whether ants captured in the vicinity of a hospital Presidente Prudente - SP are carriers of potentially pathogenic bacteria. The ants were withdrawn with a sterile swab and transferred to test tubes containing TSB (tryptone soy broth) and incubated at $37^{\circ} \mathrm{C}$ for 24 hours. Subsequently seeded in appropriate culture media and all the tests carried out to identify the bacteria. Was founded $26 \%$ of potentially pathogenic bacteria of the species Staphylococcus saprophyticus (11\%), Staphylococcus epidermidis (1\%), Enterobacter spp (3\%) and Klebsiella spp (11\%). It was concluded that the ants captured around in Presidente Prudente hospital carry potentially pathogenic bacteria.
\end{abstract}

Keywords: Ants, Hospital infection, Bacteria. 


\section{INTRODUÇÃO}

Com o crescimento acelerado de áreas urbanas, tem-se notado deficiência da qualidade do saneamento básico, com isso ocorrendo a proliferação de alguns vetores, o desmatamento fez com quem esses insetos, de fácil adaptação em grandes centros, migrassem tanto para residências quanto para o ambiente hospitalar ${ }^{1}$. Dentre esses vetores tem chamado a atenção dos pesquisadores as formigas, pois são consideradas carreadoras de microrganismos principalmente no âmbito hospitalar, pois tem grande mobilidade, podendo percorrer até três centímetros por segundo ${ }^{2}$. Muitos fatores influenciam a presença de formigas no ambiente hospitalar, dentre eles a estrutura arquitetônica, alimentos armazenados em locais impróprios, caixas de papelão com ninho, embalagens de medicamentos e o grande fluxo de pessoas ${ }^{2}$.

As formigas se movimentam de lugares contaminados para lugares não contaminados, carreando assim os microrganismos de um local sujo para um local limpo, tornando um agravo ao ambiente hospitalar; sendo assim são consideradas vetores mecânicos pois são carreadoras de microrganismos patogênicos ${ }^{3}$.

A necessidade do estudo tornou-se interessante para avaliar seu possível envolvimento como vetores de patógenos, podendo causar assim uma infecção hospitalar, a presença de formigas em ambiente hospitalar não significa que o local seja precário de limpeza, algumas espécies apresentam afinidade por locais higienizados e materiais estéreis ${ }^{4}$.

Dentre os microrganismos que podem ser carreados nas formigas, os fungos são de menor importância, sendo encontradas em maior quantidade bactérias patogênicas oportunistas ${ }^{3}$.

Por meio das relações entre saúde, sociedade e ambiente podemos observar a associação de doenças (infecciosas) em diferentes territórios. Essa associação pode ser analisada em diferentes escalas, desde o local ao global. Microrganismos podem ser encontrados dentro e fora de hospitais, o que permite o planejamento de ações com a finalidade de estabelecer diagnósticos para a obtenção da saúde, levando a melhores condições de vida para a população. Fica evidente, portanto, que é fundamental para a promoção de saúde e a compreensão da saúde ambiental, o desenvolvimento de um planejamento de ações junto a população para melhorias na qualidade de vida ${ }^{5}$.

Infecção hospitalar é qualquer infecção adquirida durante a internação do paciente, podendo se manisfestar durante o período da internação ou após a alta ${ }^{6}$ geralmente causada pela própria microbiota humana, através de procedimentos invasivos ou contato com patógenos externos, do ambiente hospitalar.

As infecções de serviços de saúde, são consideradas como um problema de saúde pública relacionados com morbidade e mortalidade, devido os problemas emocionais e socioeconômicos do paciente, família e comunidade ${ }^{7}$. Todo esse movimento resultou, inclusive, na modificação do conceito de saúde.

Portanto, podemos considerar que o microrganismo, assim como sua distribuição no espaço e tempo, torna-se um componente importante para o atual conceito de saúde.

As infecções hospitalares têm crescido principalmente por causa de tecnologias com procedimentos invasivos (sondas, cateteres dentre outros) ${ }^{2}$.

Os sítios mais frequentes de infecção hospitalar são trato urinário, feridas cirúrgicas e trato respiratório. Os patógenos Gram negativos mais encontrados são Escherichia coli: trato urinário, feridas cirúrgicas e sangue; Pseudomonas spp.: trato urinário, trato respiratório e queimaduras; Klebsiella spp.: trato urinário, trato respiratório e feridas cirúrgicas; Enterobacter spp.: trato urinário, trato respiratório e feridas cirúrgicas; Serratia spp.: trato urinário, trato respiratório, feridas cirúrgicas. Para as bactérias Gram positivas, Streptococcus spp. é responsável pelas infecções no trato urinário, trato respiratório e feridas cirúrgicas; Staphylococcus aureus: pele, feridas cirúrgicas e sangue e Staphylococcus epidermidis: pele, feridas cirúrgicas e sangue) ${ }^{8}$. Sendo 
assim, se algumas dessas bactérias forem carreadas pelas formigas aumentará o risco de infecção hospitalar.

Podemos verificar, portanto, que microrganismos, são de fundamental importância como fator de risco à saúde da população e para prevenir riscos biológicos podemos utilizar os conceitos de biossegurança e aliado ao mesmo os programas de qualidade, que podem auxiliar no controle de riscos e na qualidade de ambientes dentre outros fatores ${ }^{9}$.

A compreensão das formigas como vetores de doenças tem implicações importantes para as medidas de controle. Para isso, torna-se necessário documentar a disseminação espacial de clones no ambiente externo de um hospital contribuindo para a promoção da saúde da população que utiliza a área geográfica do estudo.

A associação entre formigas e seres humanos tem crescido cada dia mais devido ao processo de urbanização. Incidentes ocasionados pelas formigas tem-se tornado mais frequente, sendo assim, a necessidade da compreensão de seus hábitos é um fator importante para a diminuição de riscos de transmissões de vetores patogênicos em ambiente hospitalar ${ }^{3}$.

Formigas são insetos que se adaptaram ao ambiente e ao homem, devido à urbanização. Por possuírem mobilidade conseguem disseminar microrganismos, como bactérias, envolvidas com infecções hospitalares (IH). Os estudos envolvendo formigas em hospitais mostram relevância devido ao potencial destas na transmissão de $\mathrm{IH}$.

As bactérias veiculadas pelas formigas encontradas no entorno hospitalar, são representadas pelos grupos bacterianos Gram positivos e Gram negativos, as mesmas encontradas dentro dos hospitais relacionadas com diversos tipos de infeç̧ões hospitalares, um grave problema de saúde pública, pois os pacientes internados, normalmente já estão com a saúde debilitada e os agentes infecciosos tendem a ser mais resistentes que o comum.

Sendo assim o presente estudo se propôs a avaliar se formigas capturadas no entorno de um hospital de Presidente Prudente - SP são transportadoras de microrganismos, bem como identificar e verificar a prevalência dos microrganismos veiculados pelas formigas no entorno hospitalar.

\section{MÉTODOS}

A coleta foi realizada no período matutino, no entorno de um hospital de Presidente Prudente em que coletou-se um total de 100 formigas, sendo 25 do acesso a entrada principal, 25 do acesso a emergência, 25 do acesso ao ambulatório e 25 do acesso à hemodiálise. E 10 formigas foram coletadas de locais distantes do hospital e utilizadas para controle da pesquisa.

A coleta das formigas foi realizada com o auxilio de um swab estéril e transferidas para tubos de ensaio contendo TSB (caldo de triptona de soja), e transportado até o laboratório de Microbiologia, da Unoeste, e foram incubadas em estufa $36 \pm 1$ 으 (18-24h). Após incubação em TSB, todas as amostras positivas foram semeadas em ágar sangue e incubadas em estufa $36 \pm 1$ 으 (18-24h) e submetidas à coloração de GRAM. Para a identificação das bactérias potencialmente patogênicas as colônias de bacilos Gram-negativos foram semeadas em MacConkey e nas provas bioquímicas para identificação das mesmas e as colônias de cocos Gram-positivos, sugestivos de estafilococos, foram semeadas nas provas bioquímicas específicas ${ }^{10}$.

\section{RESULTADOS}

100 formigas de várias espécies não identificadas, foram capturadas assepticamente, em 4 locais distintos no entorno de um hospital de Presidente Prudente. Desse total 25 foram coletadas na porta que dá acesso a entrada principal, 25 no acesso ao ambulatório, 25 no acesso da hemodiálise e 25 no acesso da emergência. A partir da observação das características morfotintoriais, pela coloração de GRAM, observou-se $70 \%$ bacilos Gram positivos esporulados, 
$12 \%$ cocos Gram positivos sugestivos de estafilococos, $14 \%$ bacilos Gram negativos e $04 \%$ com ausência de crescimento(Figura 1).

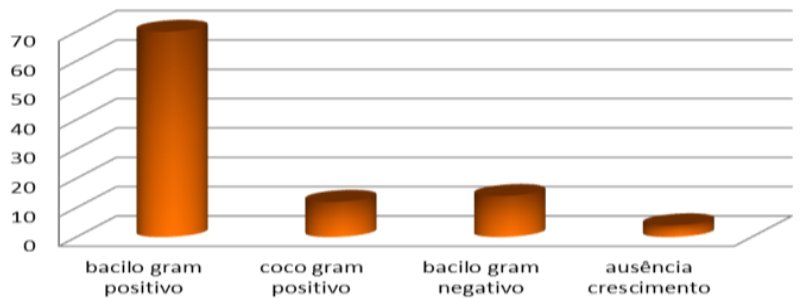

Figura 1. Porcentagem total pela observação da coloração de Gram, de microrganismos encontrados nas formigas provenientes do entorno hospitalar.

Após incubação em meio de cultura, das 100 formigas $26 \%$ apresentaram crescimento de microrganismos e foram isoladas cepas de Estafilococos coagulase negativo das espécies Staphylococcus saprophyticus, 11\%, Staphylococcus epidermidis, 1\%, estes representantes do grupo de cocos Gram positivos totalizando 12\%; e Enterobacter spp., 3\%, e Klebsiella spp., 11\%, pertencentes ao grupo dos bacilos Gram negativos, da família Enterobacteriaceae totalizando $14 \%$ (figura 2).

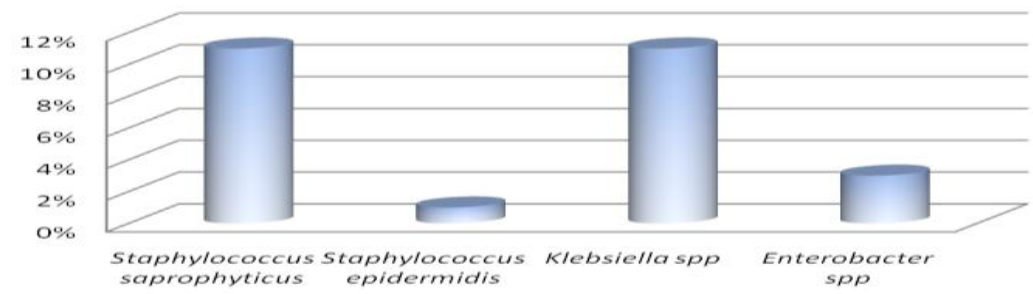

Figura 2. Porcentagem por espécie bacteriana isoladas das formigas do entorno hospitalar.

Em relação aos locais onde foram coletadas as formigas, quanto ao crescimento de microrganismos foram encontradas os seguintes resultados: $11 \%$ na porta de acesso da emergência, representando $03 \%$ de cocos e $08 \%$ de bacilos; $04 \%$ no acesso ao ambulatório, representando $01 \%$ de cocos e $03 \%$ de bacilos; 08\% no acesso da recepção, representando 08\% de cocos e $03 \%$ no acesso a hemodiálise, representando $03 \%$ de bacilos (figura 3 ) .

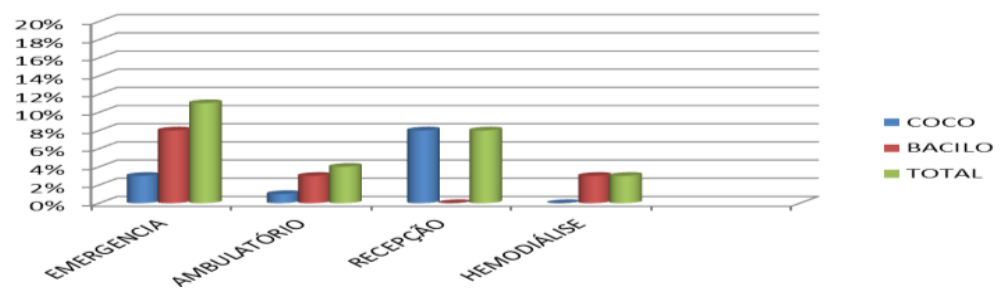

Figura 3. Porcentagem por grupo bacteriano, isolados de culturas das bactérias encontradas nas formigas provenientes de cada acesso do entorno hospitalar.

Nesta pesquisa 4\% dos tubos de TSB com formigas não apresentaram crescimento bacteriano. E os grupos controles tiveram crescimento de bacilos Gram positivos esporulados e não houve crescimento de microrganismos. 


\section{DISCUSSÃO}

Considerando os locais de coleta das formigas, houve crescimento bacteriano em $96 \%$ das amostras, sendo $70 \%$ de bacilos Gram positivos esporulados, consideradas bactérias transitórias do ambiente de adaptação destas formigas são microrganismos presentes no ambiente e $26 \%$ foram bactérias potencialmente patogênicas, demonstrando não haver um alto índice de contaminação bacteriana nas formigas do entorno hospitalar desta pesquisa. Baseados nestes dados, podemos afirmar que as formigas são transportadoras, ou seja, veiculadoras mecânicas de microrganismos. Verificou-se prevalência de bacilos Gram negativos, da família Enterobacteriaceae (14\%), seguido de $12 \%$ dos cocos Gram positivos agrupados, os Estafilococos coagulase negativa. E $4 \%$ das amostras não houve crescimento bacteriano ${ }^{11}$ que foi de $5 \%$ de ausência.

Dos achados laboratoriais desta pesquisa, após a identificação bacteriana, observou-se menor crescimento de bactérias patogênicas em relação aquelas presentes no ambiente, assim como revelados em outros trabalhos. ${ }^{1,8,12}$. Foram isoladas nesta pesquisa espécies bacterianas potencialmente patogênicas, causadoras de infecções hospitalares. Identificadas no grupo dos bacilos Gram negativos, foram Klebsiella spp. (11\%) e Enterobacter spp. (3\%), e enquadradas no grupo bacteriano das Gram positivas, Staphylococcus saprophyticus (11\%) e Staphylococcus epidermidis (1\%), portanto, predominantemente Klebsiella spp. e Staphylococcus saprophyticus ${ }^{13 .}$ Os Staphylococcus saprophyticus, são causadores de infecções agudas do trato urinário em mulheres jovens, sadias e sexualmente ativas ${ }^{10}$. As espécies de bactérias pouco prevalentes, foram Enterobacter spp. responsáveis por causarem infecções hospitalares, no trato urinário e os Staphylococcus epidermidis, causadores de infecções de pele e feridas cirúrgicas ${ }^{8}$, bacteremias ${ }^{14}$ e endocardites ${ }^{13}$.

Os dados coletados, revelaram que todos os locais de acesso e de coleta das amostras do entorno hospitalar, apresentaram crescimento bacteriano, mesmo que este local tenha contaminantes representados por apenas um dos grupos bacterianos identificados. A fig. 3 demonstra que a prevalência de bactérias potencialmente patogênicas isoladas foi maior na emergência, com predomínio de cepas de bacilos Gram negativos; seguindo a recepção com crescimento cepas de cocos Gram positivos; o ambulatório, predominantemente de cepas de bacilos Gram negativos e a hemodiálise somente com crescimento de cepas de bacilos Gram negativos.

Com este estudo verificou-se que a emergência e a recepção são os locais de acesso, de maiores índices de formigas contaminadas, refletindo nos locais de maior acesso da população. Desta maneira, os locais de pouco acesso populacional, são o ambulatório e a hemodiálise, corroborando com nossos dados que demonstraram menor prevalência de isolamento de bactérias potencialmente patogênicas. Portanto, os microrganismos isolados e identificados, estão ligados ao risco de problemas no ambiente hospitalar.

E considerando que as formigas possuem mobilidade e podem ser encontradas em vários lugares e no hospital não é diferente, pois tem sua entrada facilitada por serem atraídas não somente por alimentos e lixos, mas também por materiais esterilizados que encontram-se dentro do hospital, fator ainda mais preocupante, essas formigas podem levar para o interior do hospital vários tipos de microrganismos, dentre eles, bactérias que são potencialmente patogênicas, sendo assim são importantes transmissoras de doenças ${ }^{1}$, ocasionando problemas de ordem à saúde pública no nosso país ${ }^{3}$.

Concluiu-se que $26 \%$ das formigas capturadas no entorno de um hospital em Presidente Prudente, transportavam microrganismos, sendo mais prevalentes os bacilos Gram negativos da família Enterobacteriacea (14\%). Quatro por cento das formigas analisadas não transportavam microrganismos. 


\section{REFERÊNCIAS}

1. Fontana R, Wetler RMC, Aquino RSS, Andrioli JL, Queiroz GRG, Ferreira SL et al . Disseminação de bactérias patogênicas por formigas (Hymenoptera: Formicidae) em dois hospitais do nordeste do Brasil. Neotrop. entomol. [Internet]. 2010 Aug; 39( 4 ): 655-663. Available from: http://www.scielo.br/scielo.php?script=sci_arttext\&pid=S1519-566X2010000400029\&lng=en. http://dx.doi.org/10.1590/S1519-566X2010000400029.

2. Tanaka II, Viggiani AMFS, Person OC. Bactérias veiculadas por formigas em ambiente hospitalar. Arq Med ABC.2007; 32(2): 60-63.

3. Castro MM De, Fernandes EF, Prezoto HHS, Prezoto F. formigas em ambientes urbanos : importância e risco à saúde. CES REVISTA, 2014; 28 (1): 103-117.

4. Maia ZPG, Gusmão AB, Barros TF; Formiga como fator de risco para infecções nosocomiais. SaBios: Rev. Saúde e Biol. jul./dez. 2009, 4 (2): 47-51.

5. Pereira RR. Território, saúde e ambiente: novas formas de articulação. GEOGRAFIA, Londrina, 2009; 18 (1): 193-206.

6. Freire RS, Levada MMO, Beretta ALRZ. Formigas como vetores mecânicos de bactérias em ambiente hospitalar. ÁGORA Revista Eletrônica, 2013; 16 (1): 62-66.

7. Oliveira AC, Damasceno QS. Superfícies do ambiente hospitalar como possíveis reservatórios de bactérias resistentes: uma revisão. Rev Esc Enferm USP, 2010. v. 44 (4): 11181123. https://doi.org/10.1590/S0080-62342010000400038

8. Teixeira MM. Formigas como carreadoras de microorganismos no Hospital Escola da Universidade Federal do Triângulo Mineiro [Monografia (Mestrado em Patologia)]. Universidade Federal do Triângulo Mineiro, Uberaba; 2007.

9. Hokerberg YH. et al. O processo de construção de mapas de risco em um hospital público. Cien Saude Colet, 2006. v. 11 (2): 503-513. https://doi.org/10.1590/S1413-81232006000200027

10. Koneman EW, Allen S D, Woods GL. Koneman diagnóstico microbiológico : texto e atlas colorido, 6a ed. Medsi, 2008.

11. Vieira GD ,et al.Bacterias Gram positivas veiculadas por formigas em ambiente hospitalar de Porto Velho, estado de Rondônia, Brasil. Rev. Pan-Amaz Saude. set. 2013; 4 (3).

12. Jacobs $C$, Alves IA. Identificação de microrganismos veiculados por vetores mecânicos no ambite hospitalar em uma cidade da região noroeste do estado Rio Grande do Sul. Rev Epidemiol Control Infect. 2014;4(4):238-242.

13. Rosado JLO, Bastos CP, Bassani MT. Associação entre formigas (Hymenoptera: Formicidae) e bactérias patogênicas em cinco hospitais do município de Pelotas, RS. Arq. Inst. Biol. [Internet] , 2011. v. 78 (2): 287-295.

14. Pereira RS, Ueno M. Formigas como veiculadoras de microrganismos em ambiente hospitalar. Rev. Soc. Bras. Med. Trop. [Internet]. 2008 Oct; 41( 5 ): 492-495. Available from: 
http://www.scielo.br/scielo.php?script=sci_arttext\&pid=S0037-86822008000500011\&lng=en .

http://dx.doi.org/10.1590/S0037-86822008000500011. 